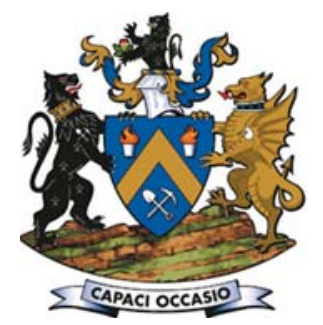

\title{
Tiger's eye in the Northern Cape Province, South Africa - grading, distribution, small-scale mining, and beneficiation potential
}

\author{
by S. Rasmeni*, D. Chetty*, P. Sebola*, and K. Seripe*
}

\section{Synopsis}

South Africa's Northern Cape Province hosts semi-precious and gemstone occurrences that are sporadically mined on a small scale by local communities. Tiger's eye, a gemstone known for its chatoyancy properties, is found in important deposits located near the town of Prieska, where is it intermittently mined. Challenges faced by small-scale and informal mining include mining without proper permits, risky mining practice in dangerous terrain, and illegal export of raw material without concerted effort at domestic beneficiation. As part of a study aimed at job creation and social upliftment in the region, tiger's eye deposits in the Prieska area were assessed to assist small-scale miners to understand tiger's eye grades and their distribution. This will allow not only more efficient and safer mining of these deposits, but also beneficiation of the raw product into tumbled stones, cabochons, jewellery, and other small artefacts for sale. A hub established in Prieska by Mintek trains locals in the beneficiation of tiger's eye. Supply to the hub must make use of a consistent grading system, which is discussed in this paper. Together with proper mine licensing, such an approach will develop mining and beneficiation skills, and create and sustain employment for the local community.

Keywords

Tiger's eye, grading, beneficiation, small-scale mining.

\section{Introduction}

Tiger's eye is a semi-precious stone known for its chatoyancy property, which is caused by parallel, silicified asbestos fibres that impart a silky lustre to specimens. Deposits of tiger's eye in the surrounds of the town of Prieska, Northern Cape Province, formed the focus of a study aimed at small-scale mining and beneficiation of this commodity. The Prieska tiger's eye deposits are located along the $\mathrm{N} 10$ route to Upington (Figure 1). Tiger's eye is unevenly distributed and occurs as lenses of various sizes, interbedded in gently folded metasedimentary rocks of mostly banded iron formation (BIF). The tiger's eye occurrence in the Northern Cape Province, especially in the Prieska area, has not been extensively researched. There is thus limited information available in the public domain. The lack of knowledge on tiger's eye distribution has resulted in local small-scale miners adopting a trial-and-error method of mining. Basic geological mapping and field evaluation of the deposit, coupled with professional judgement, are important aspects of any small-scale mining operation and can contribute significantly to the formulation of various acceptable and equally viable mining methods and practices.

A recent study by Ledwaba (2014) was aimed at documenting brief introductory details on tiger's eye mining and its potential for employment creation and poverty alleviation in the Prieska area. In the past, studies were undertaken by Mintek with the aim of grading tiger's eye in the Northern Cape (Kleyenstüber, 1990; Pillay and Thompson, 2008). This was after Mintek realized that a proper grading and pricing system for raw tiger's eye was lacking. According to information from local miners, the grades and prices remain dictated by foreign buyers, who export the material to countries like China, the UK, and Italy to be beneficiated.

This paper provides outcomes from fieldwork that was designed to evaluate and map tiger's eye deposits located in areas to the west and northwest of Prieska, and to explore artisanal mining activities in the area, with a view to understanding the geology, mining methods, distribution of mineralization, and ultimately, the sustainability of the operations in terms of tiger's eye supply. Furthermore, a standard grading system based on scientific observations has been refined, based on samples sourced from various suppliers in the Prieska area. These samples are graded based on bench-scale tumbling and polishing tests in order to match the in situ estimation of grade with tumbled product quality. In the absence of an international standardized grading system, a consistent grading system that is fully understood by suppliers, miners, and buyers is recommended.
* Mineralogy Division, Mintek, Randburg, South Africa.

(C) The Southern African Institute of Mining and Metallurgy, 2016. ISSN 2225-6253. Paper received Aug. 2015; revised paper received Nov. 2015. 


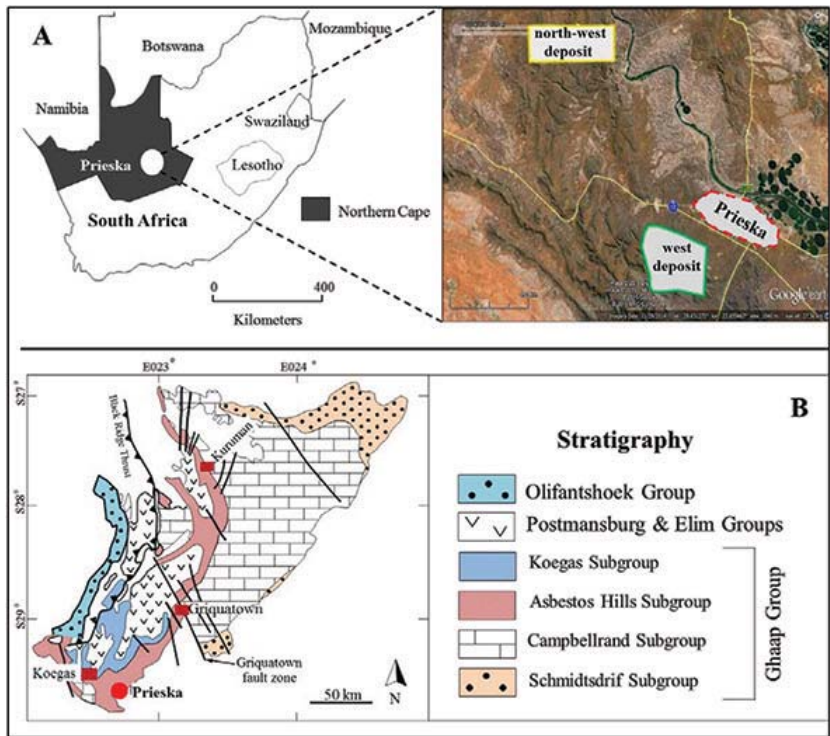

Figure 1-(A) Locality map of South Africa, showing the Northern Cape Province and the Prieska area. The Google Earth image shows the locality of the two mapped tiger's eye deposits. (B) Geological map and stratigraphic column showing the Asbestos Hills Subgroup, which hosts the tiger's eye deposits (modified from Schröder et al., 2011)

\section{Geological setting and occurrence}

The deposits are hosted in BIF of the Asbestos Hills Subgroup within the the Ghaap Group, which is overlain by the Postmasburg and Elim Groups, and Olifantshoek Group of the Transvaal Supergroup. The Asbestos Hills Subgroup within the Ghaap Group is underlain by the Schmidtsdrif and Campbellrand subgroups and is overlain by the Koegas Subgroup (Figure 1A). The surface geomorphology is characterized by mountainous terrain. The surface geology is largely dominated by unconsolidated aeolian sands and calcretes. Together, they mantle the BIF, which is distributed in patchy erosional remnants rather than in large continuous units.

Associated with the tiger's eye seams are pockets containing crocidolite asbestos (unsilicified material) that could pose a health risk to miners trying to dislodge the tiger's eye from the seams. The Prieska tiger's eye deposits are characterized by numerous active and abandoned diggings, some of which have been abandoned due to lack of proper mining equipment and technology to expose and extract the seams. If the tiger's eye seam dips steeply, the miners are forced to abandon the area as they cannot remove the thick overburden.

\section{Tiger's eye distribution}

Although other tiger's eye occurrences have been reported on numerous private farms in the Prieska area, two major deposits occur on communal land. The first deposit is located west of Prieska, and the second deposit is located towards the northwest (Figure 1B). The BIF units that host tiger's eye are separated by a pediment surface covered by vegetation and, in some places, unconsolidated, reddish-brown to grey aeolian sands and gravel. Three types of tiger's eye occur in the area. These are blue tiger's eye (silicified crocidolite); yellow tiger's eye, and variegated tiger's eye (a mixture or intergrowth of yellow and blue tiger's eye with sharp contacts between them). The yellow type is the more sought-after variety, although the silicified blue (crocidolite) and variegated material are also required by the world market. Additionally, fibrous tiger's eye is encountered in the outcrops, where unsilicified asbestiform fibres are present. A more systematic method of grading the yellow variety of tiger's eye according to its thickness, lustre, and nondeformity of the fibres has been investigated by Mintek in the past and a refinement of this method is presented later in this paper.

\section{Prieska west deposit}

The study area, which covers an area of approximately $32 \mathrm{~km}^{2}$, is located between $5 \mathrm{~km}$ and $15 \mathrm{~km}$ west of Prieska with a boundary along the N10 highway to Upington (Figure 1B). This is the more intensively exploited deposit of the two studied, and occurs at elevations between $980 \mathrm{~m}$ and $1280 \mathrm{~m}$ with thickness varying between $2 \mathrm{~cm}$ and $5 \mathrm{~cm}$.

Mineralization is hosted in fold-related structures that are associated with faulting. Folds and fold-related veins strongly control the location of these deposits. The weathered and calcretized BIF is well exposed in most excavations studied and occurs interbedded mostly with tiger's eye and calcretized sandy soil and gravel. Therefore, the geology throughout the study area, especially the low-lying areas, is dominated by alternations of calcareous and calcified soil and gravels, deeply weathered and calcretized BIF, and calcrete hardpan.

Mining in weathered and calcretized BIF is relatively easy, but also risky, since the overburden is prone to collapse. Weathered BIF is relatively soft, whereas sandy, calcareous soils that have an open voided grain structure, with the individual grains being separated by a bridging material (such as loose powder calcrete or calcite) possess a collapsible fabric (Figure 2). This bridging material loses strength and rapid settlement may take place if such soils are exposed to increased moisture content under load. On the other hand, mining in calcrete hardpan (hardened calcareous soils) areas using simple equipment such as picks and shovels could be a futile exercise since the ground is rigid and compacted. 


\section{Tiger's eye in the Northern Cape Province, South Africa}

The occurrence of various types of tiger's eye in the Prieska west area is presented in the form of a geological map in Figure 3. The information on the map is based on the tiger's eye seams exposed on the surface and the distribution

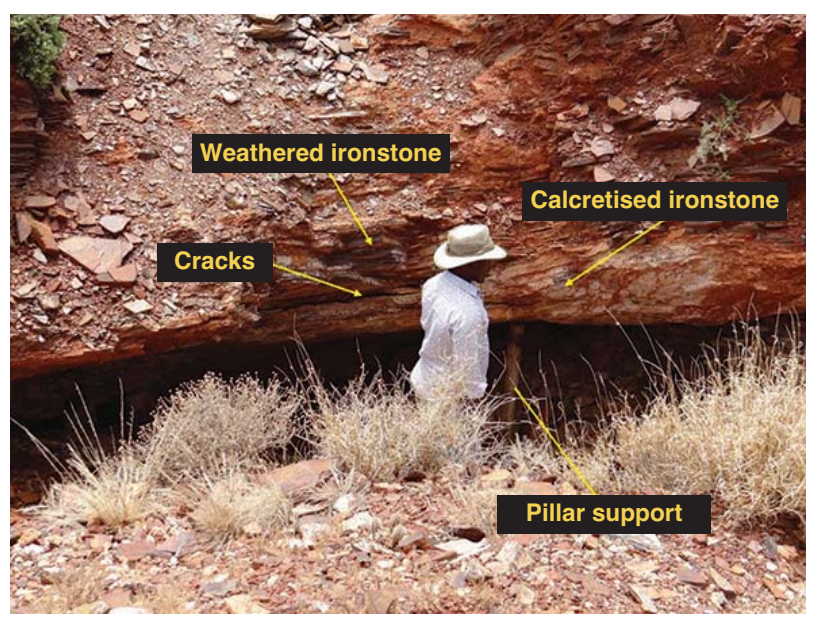

Figure 2-Hanging overburden resulting from tiger's eye mining, with poor support of previous mining activities. Seventy-five excavations/ trenches measuring $1.5-70 \mathrm{~m} \times 2-2.5 \mathrm{~m} \times 0.5-3 \mathrm{~m}$ were evaluated. The various BIF units hosting tiger's eye are categorized as follows: high-grade zones (approx. 80\% yellow, $18 \%$ blue/variegated, and 2\% fibrous tiger's eye occurrences); low-grade zones (approx. 40\% yellow, 50\% blue/variegated, and 10\% fibrous tiger's eye), and fibrous zones (approx. 10\% yellow, 60\% blue/variegated, and 30\% fibrous tiger's eye). The fibrous type is restricted to the south to southwest portion, in the vicinity of the abandoned asbestos mine.

\section{Prieska northwest deposit}

The Prieska northwest deposit is located about $35 \mathrm{~km}$ northwest of the Prieska community area. The total claim area, which comprises the Geduld farm, covers an extent of between $15 \mathrm{~km}^{2}$ and $18 \mathrm{~km}^{2}$ and is set in mountainous and faulted terrain. The deposit is accessed through a single-track road, with sandy and rocky driving conditions due to high and uneven terrain.

The geology of the Prieska northwest area is presented in the form of a geological map in Figure 4. In the northern sections of the claim area, two abandoned asbestos mines are located about a kilometre from dilapidated farmhouses. Loose

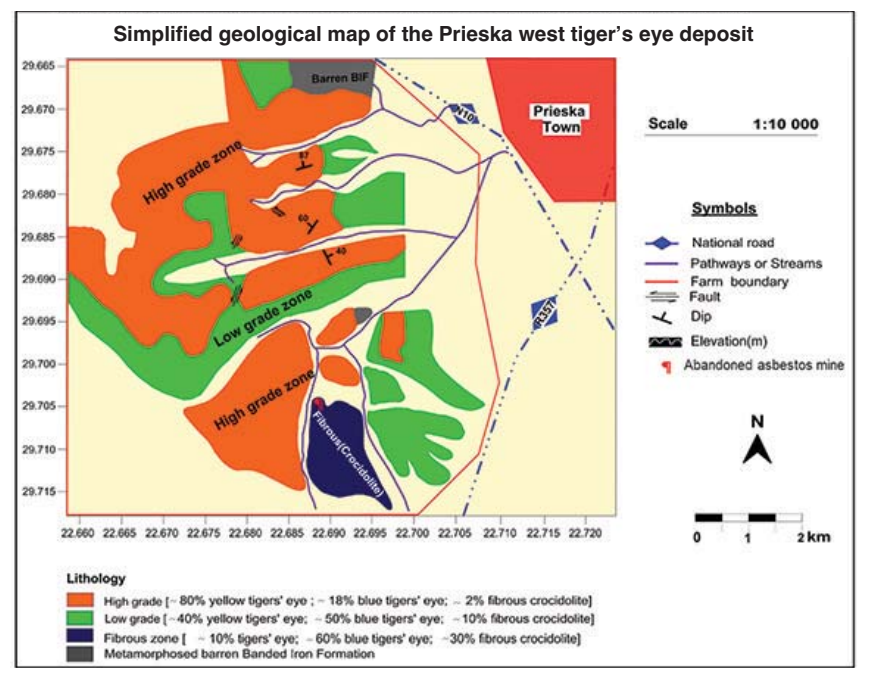

Figure 3-Geological map of the Prieska west tiger's eye deposit, showing zones of high- and low-grade tiger's eye, and asbestos-rich and barren areas

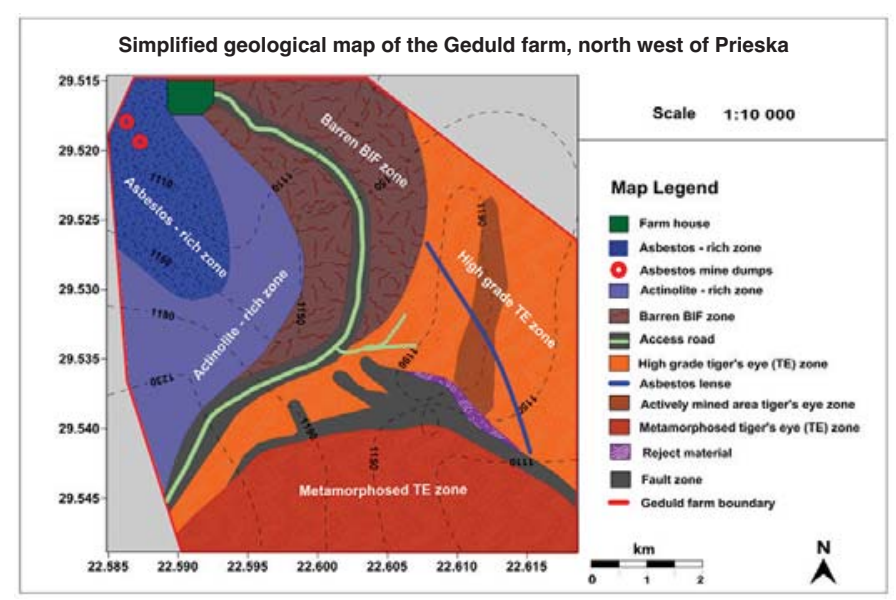

Figure 4-Geological map of the Prieska northwest tiger's eye deposit, showing zones of high-grade tiger's eye, and asbestos-rich, actinolite-rich, and metamorphosed tiger's eye zones, as well as barren areas 


\section{Tiger's eye in the Northern Cape Province, South Africa}

chert and dolomite can also be observed around the abandoned asbestos mines. The south and southeastern sections consist of approximately 25 diggings or trenches with intensely metamorphosed BIF and quartzite outcrops hosting tiger's eye.

Visible trenches and some untapped surface exposures show that two grades of tiger's eye occur in the area: high grade, which is restricted to the centre and eastern portion, and reject material towards the southern portion of the farm boundary. The reject material observed in this area is unique, in that it resembles the high-grade material but lacks chatoyancy, which is the main feature of tiger's eye. The absence of the chatoyancy effect can be attributed to intense metamorphism. Fibre bundles are distorted, resulting in difficulty in separation from the country rock, and this renders reject material unusable in the gemstone industry. Folds and vein-related structures strongly control the location of the tiger's eye deposits in this area.

\section{Tiger's eye grading}

Grading of tiger's eye is focused mainly on the yellow or golden yellow variety since this is most sought-after.

Although a systematic grading method based on physical and mineralogical characteristic has been developed by Mintek in the past (Kleyenstüber, 1990), ambiguous tiger's eye grading systems still exist among various small-scale miners. Their grading system is based on the individual's experience. In a normal situation, the price of each product should be influenced by grade. However, circumstances such as market supply vs. demand, the financial situations of the seller and buyer, and their relationship often play a role in the pricing. Various grades of tiger's eye were sourced from different suppliers in the Prieska area. The main aim was to compare the quality of various stones purchased, as per local grading, with the Mintek grading system.

Currently, yellow tiger's eye material from the Prieska area is graded based on physical appearance into three grades, in order of decreasing quality: A, B, or C. The A grade is further categorized into A1 (lowest quality), A2, A3, and A4 (highest quality), and B grade is subdivided into B1, B2, $B 3$, and B4, based on the thickness of the seam, as shown in Table I. The A4 and B4 grades are reportedly rare.

Table I

\section{Grades and standardized prices of tiger's eye from} Prieska suppliers

\begin{tabular}{|l|c|c|}
\hline Description & Thickness $(\mathbf{m m})$ & Price per $\mathbf{k g}$ (rands) \\
\hline A1 or (A medium) & $10-19$ & 25 \\
A2 & $20-24$ & 30 \\
A3 & $25-32$ & 35 \\
A4 & $>32$ & $40-50$ \\
B1 or B medium & $10-19$ & 15 \\
B2 & $20-24$ & 18 \\
B3 & $25-32$ & 20 \\
B4 & $>32$ & $22-25$ \\
\hline
\end{tabular}

${ }^{*}$ Rare/uncommon in this area.

\section{Criteria for tiger's eye grading}

Chatoyancy creates the attractive visual effect for which tiger's eye is known. However, this effect can be altered by the slightest orientation change of a single fibre, incomplete silicification, and the grain size and orientation of the replacing mineral, quartz. In low-grade tiger's eye specimens, thick fibres, incomplete silicification, and size and orientation of quartz replacement can be easily observed. In a high-grade material, such characteristics are observed under the petrographic microscope, as they occur on a very limited scale. Microscopic features do not have a major impact on the price or quality of tiger's eye and many of them do not directly affect the chatoyancy.

The following characteristics are used during tiger's eye grading (Kleyenstüber, 1990; Pillay and Thompson, 2008):

> Colour - the golden or honey yellow and light brown colours are the most valuable and are also more prized than blue or variegated material

> Length of fibre - thin seams $<10 \mathrm{~mm}$ are generally considered as reject material, and the fibres that are $>100 \mathrm{~mm}$ are the most valuable

- Chatoyancy lines - graded according to frequency and sharpness. Material with sharp lines is more valuable than that with diffuse lines. High-quality tiger's eye should have numerous straight and sharp chatoyancy lines, whereas lower quality specimens will have broken or wavy lines

- Fibre orientation in relation to the host rock-fibre orientation affects the cutting of the gemstone. The fibres should be oriented perpendicular to the bedding in the host rock, otherwise chatoyancy is reduced. For high-quality material, the fibre length orientation should not be greater than $5^{\circ}$ to the bedding. Kinks and bends also decrease the quality of specimens

- Macro inclusions - macro and micro inclusions are also considered during tiger's eye grading. Macro inclusions are cracks, holes, and pit marks, which will have a definite detrimental effect on the beneficiated product. Such inclusions on the micro scale are best viewed under the optical microscope

> Silicification-silicification should be complete, with no asbestos fibre remaining

> Texture-fine-textured fibre bundles show the best play of light, whereas coarse-textured material, as well as incomplete silicification, will cause problems during cutting and polishing.

\section{Prieska suppliers vs. Mintek's grading system for tiger's eye}

Table II summarizes Mintek's grading of tiger's eye using the A, B, C, and reject material classifications. This was the benchmark against which raw material purchased from different local suppliers was compared. The various categories of A-grade tiger's eye material (as per supplier classifications), consisting of A1, A2, and A3, were cut and polished, with some tumbled (Figure 5), to observe the consistency of the appearance of the final product. Based on the polished and tumbled pieces, the physical characteristics of the A-grade categories are all similar to that of the Mintek A-grade classification. The only difference is the thickness of 


\section{Tiger's eye in the Northern Cape Province, South Africa}

\begin{tabular}{l} 
Table II \\
Mintek's grading system for tiger's eye (Kleyenstüber, 1990; Pillay and Thompson, 2008; present study) \\
\hline \multirow{2}{*}{ Grade }
\end{tabular}

$1^{*}=$ Strong visual effect

Minerals* Mineral inclusions include quartz, magnetite, and goethite

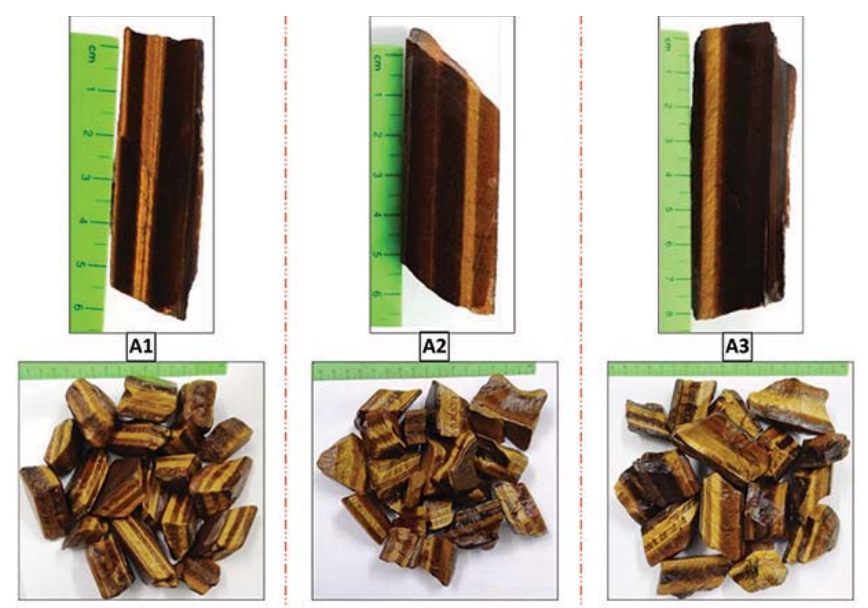

Figure 5-Polished pieces of tiger's eye (top) and tumbled products (bottom) of A-grade sub-types

the seam in each category. The A1 grade varies in thickness from $1 \mathrm{~cm}$ to $1.9 \mathrm{~cm}$, whereas the A2 grade has a thickness of about $2 \mathrm{~cm}$ to $2.4 \mathrm{~cm}$, and A3 varies from $2.5 \mathrm{~cm}$ to $3.2 \mathrm{~cm}$ in thickness. Except for seam thickness, there is no observable distinction between the A-grade sub-categories.

The B-grade material is subdivided into B1 and B2 (Figure 6) based on the thickness. The physical characteristics of the B1 material are equivalent to the Mintek B-grade classification, and the seam thickness varies from $1 \mathrm{~cm}$ to 1.9 $\mathrm{cm}$. On the other hand, the B2 grade varies in thickness from $2 \mathrm{~cm}$ to $2.4 \mathrm{~cm}$ and the physical characteristics do not meet the Mintek classification for B-grade material. These samples are characterized by numerous black lines and inclusions of iron oxide, hydroxide, and quartz. Furthermore, they polish poorly due to the presence of coarse fibre bundles. Apart from that, veins cut across the material and possess wavy fibre bundles. Therefore, the above characteristics for B2grade material are equivalent to those of $\mathrm{C}$-grade material in the Mintek grading scheme.

\section{Beneficiation potential}

A beneficiation hub was commissioned in Prieska by Mintek and the National Youth Development agency in June 2014. This hub currently trains unemployed youths from the area in a structured programme. Mintek and the Siyathemba Municipality are responsible for running the facility, with the Municipality to take over responsibilities in future. The facility is managed through a local entrepreneur in consultation with both responsible parties. Current training, done via Mintek, focuses on jewellery-making using tiger's eye sourced from the Prieska area, and finished pieces have been successfully marketed (Figure 7), typically for between R300 and R500 a piece. Training on pottery and glass bead making has been included as a value addition to the tiger's eye jewellery making. Additionally, stone cutting and jewellery production utilize other semi-precious stones sourced locally.

Marketing models are under development to promote the sale of the beneficiated products, which will range from 


\section{Tiger's eye in the Northern Cape Province, South Africa}
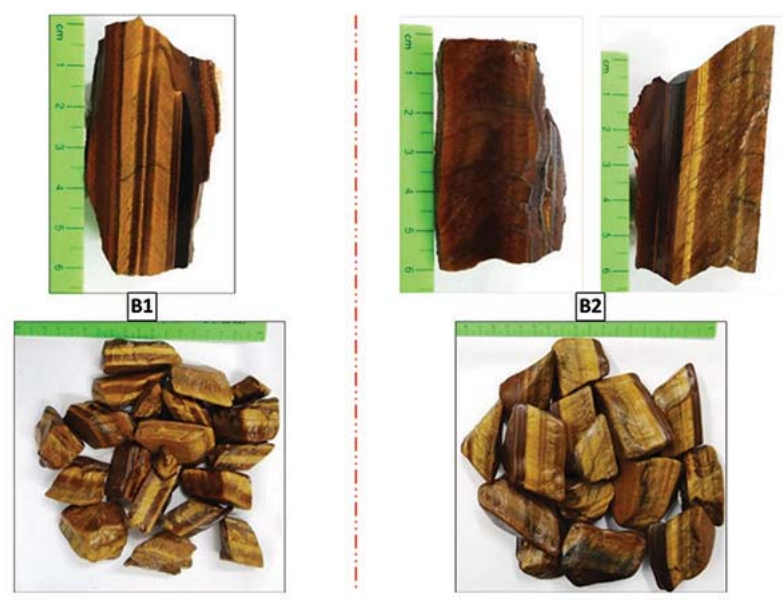

Figure 6-Polished pieces of tiger's eye (top) and tumbled products (bottom) of B-grade subtypes
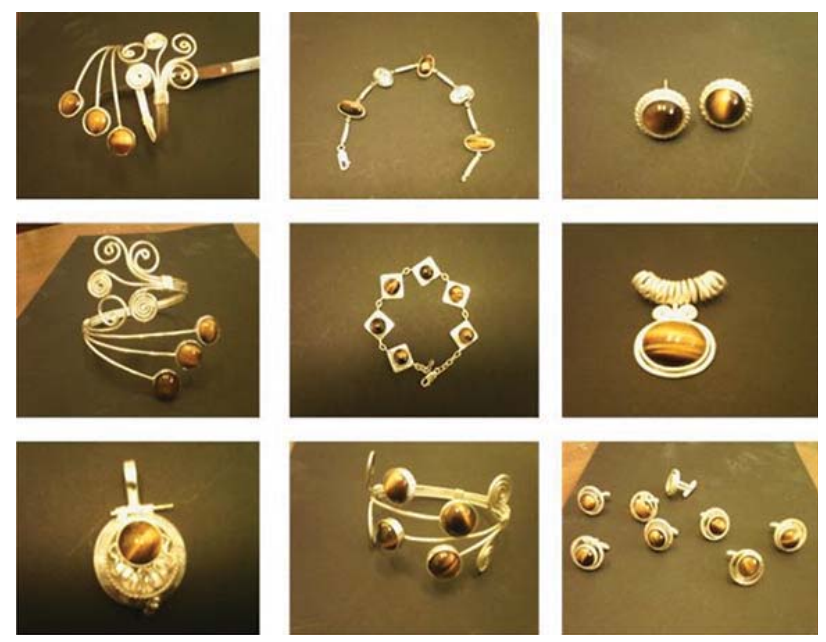

Figure 7 - Jewellery produced at the Prieska beneficiation centre, making use of tiger's eye

jewellery to small artefacts and novelties. Once in full production, the hub will bring much-needed relief and avoid exploitation of the small-scale miners by intermediate and foreign buyers. The miners will be able to sell their raw material directly to the Prieska beneficiation hub at competitive prices, through a consistent grading system understood by all. This will also ensure proper quality control of the products brought to market, and hence consistent and competitive pricing of finished products, all of which will be managed by the local learners currently in training. Ultimately, the community will thus take responsibility for the sustainability of the hub activities. If correctly managed, the Prieska tiger's eye deposit is expected to remain in production for the next 15-20 years. This, together with other tiger's eye deposits in the surrounding areas such as Niekerkshoop, will ensure a sustainable supply to, and viability of, the Prieska beneficiation hub.

\section{Conclusion}

Tiger's eye mining operations in the Prieska area continue to spread due to the increased demand for this commodity and the preference for mining over other means of livelihood such as farming in the area. While the majority of the miners continue living in extreme poverty with little or no formal education, their situation is expected to change.

The present study successfully delineated zones of high, low, and reject grades of tiger's eye in the two field areas near Prieska. The information, together with identified asbestos zones, will assist the miners to effectively and safely mine the tiger's eye. Furthermore, the refined grading scheme can be used for consistent quality assessment and pricing, and thus reduce exploitation of miners, as they will understand, and work using, the uniform system. Pricing can then be competitively done to alleviate illegal export.

Local beneficiation opportunities established through the hub in Prieska will promote skills development and job creation in the community. Training programmes will ensure that miners are regulated, and thoroughly trained in marketing, mining methods, and financial management. In this way, improved small-scale mining of these deposits can supply the beneficiation centre, and help sustain domestic beneficiation and marketing of this semi-precious stone.

\section{Acknowledgements}

The authors would like to that the following organizations and agencies for their support.

Department of Mineral Resources (DMR)

Council for Geosciences (CGS) - Upington Office

National Youth Development Agency (NYDA)

Siyathemba Municipality.

\section{References}

LedwabA, P.F. 2014. Tiger's eye in the Northern Cape Province - potential for employment creation and poverty alleviation. Journal of the Southern African Institute of Mining and Metallurgy, vol. 114. pp. 881-885.

KLEYENSTÜBER, A.S.E. 1990. A proposed grading system for raw tiger's eye. Mintek report no. M406D. Randburg. 11 pp.

Pillay, K. and Thompson, W. 2008. IM3 - mineralogy and grading of tiger's eye from the Northern Cape, South Africa. Mintek report no. 40332. Randburg.

SchröDER, S., Bedorf, D., Beukes, N.J., and Gutzmer, J. 2011. From BIF to red beds: Sedimentology and sequence stratigraphy of the Paleoproterozoic Koegas Subgroup (South Africa). Sedimentary Geology, vol. 236, no. 1-2, 15 April 2011. pp. 25-44. 